\title{
NOCIONES DE FAMILIA \\ EN EL DISCURSO DE PROFESIONALES DE TRABAJO SOCIAL EN ESPACIOS ESCOLARES
}

\author{
XIOMARA RODRÍGUEZ, FRANCIS ARAQUE, ELKIS SALAZAR \\ Escuela de Trabajo Social de la Universidad del Zulia. Venezuela.
}

\section{RESUMEN}

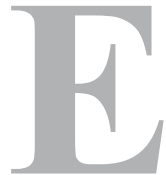

1 propósito es reflexionar sobre la noción de familia que circula en el sistema educativo como producto del discurso de la modernidad. En este discurso, la representación del "modelo ideal de familia" manifiesta una incoherencia entre la noción de familia, expresada en las construcciones teóricas y la noción manejada en la vida cotidiana. Se plantea construir un nuevo imaginario colectivo, que dé cuenta de la necesidad de revisar el discurso manejado por profesionales del Trabajo Social y otras disciplinas en espacios escolares, quienes establecen una relación en permanente construcción, donde se interrelacionan las subjetividades de todos los actores sociales concernidos en la convivialidad familiar; siendo su labor significativa en el desarrollo de una conciencia crítica, hacia la construcción de nuevas nociones de familia que expresen la vivencia social.

Palabras clave: familias, espacios escolares, trabajo social, convivialidad familiar.

\section{ABSTRACT \\ NOTIONS OF FAMILYIN THE DISCOURSE OF SOCIAL WORK PROFESSIONALS IN SCHOOLS}

The purpose of this paper is to reflect on the notion of family that exists in the education system as a product of the discourse on modernity. In this discourse, the "ideal family model" is shown to be inconsistent with the notion of family, as expressed in theoretical constructs and the notion as it is used in daily life. The proposal is to build a new collective imaginary, one that realises the need to review the discourse used by social workers and other professionals in schools, who establish relationships that are constantly being built

CORRESPONDENCIA:

Xiomara Rodríguez del Cordero

Escuela de Trabajo Social. Universidad del Zulia (LUZ)

Maracaibo, ZULIA (Venezuela)

xiodecor@hotmail.com

1 Este trabajo forma parte de las reflexiones generadas en el contexto de la línea de investigación "Representaciones, actores sociales y espacios de poder", adscrita al doctorado en Ciencias Humanas. A su vez, es parte del proyecto de investigación "Construcción de identidades en familias y otros actores sociales", financiado por el Consejo de Desarrollo Científico y Humanístico de la Universidad del Zulia (LUZ) CONDES-LUZ. 
upon, where the subjectivities of all the social actors involved in family coexistence interrelate; their most important task being to develop a critical consciousness, in order to construct new notions of family that encompass social experience.

Key words: families, schools, social work, coexistence.

\section{INTRODUCCIÓN}

En el imaginario de profesionales del Trabajo Social, la noción de familia no es unívoca, adquiere múltiples significados producidos en la realidad personal y profesional proveniente de la experiencia directa con grupos familiares. Muchos de estos significados son acallados por la tradición teórica enraizada en todo el aparato social educativo, no obstante, el cuestionamiento que actualmente acontece en las Ciencias Sociales, desde la crítica a la modernidad, abre un debate que puede ser beneficioso para la legitimación de voces diversas y plurales.

Con el propósito de reflexionar sobre la noción de familia que circula entre estos profesionales en el sistema educativo, adoptamos una perspectiva socio-histórica a partir de un diseño documental de campo en un proceso de complejidad creciente que implicó el desarrollo de varios momentos. Un primer momento, se dedicó a la recolección de información proveniente, por un lado, de la revisión de material bibliográfico, y, por el otro, de los registros de campo llevados por las autoras con un grupo de trabajadoras sociales que contactó con familias en contextos educativos durante el Seminario de Reflexión sobre Trabajo Social Familiar organizado por las autoras en el contexto del doctorado en Ciencias Humanas.

Un segundo momento, consistió en organizar la información recopilada, -estableciendo primero separaciones, de acuerdo con las variables en estudio- para, luego, reunirla en un todo coherente, mediante un proceso de análisis y discusión efectuado por el equipo de investigación. Seguidamente, en un tercer momento, se procedió a levantar el informe de investigación que se ha estructurado, para su exposición, considerando, por un lado, las reflexiones teóricas y, por el otro, la noción de familia en el discurso de las trabajadoras sociales participantes en el referido seminario.

Concluyendo con algunas reflexiones en torno al debate actual acerca de la concepción de familia como ideario forjado desde el discurso de la modernidad en los países hegemónicos, frente a otras nociones de familia pensadas desde la pluralidad y la diversidad como expresión de la vivencia social.

\section{REFLEXIONES TEÓRICAS}

Sin lugar a dudas, desde la segunda mitad del siglo XVIII y hasta fines del siglo XIX, se generaron cambios profundos en el imaginario social en relación a la concepción de familia. Estos cambios han sido analizados bajo diferentes perspectivas, desde las puramente sociológicas hasta las referencias psico-educativas, pasando por los estudios que pretenden analizar interacciones entre distintos planteamientos. Una mirada reflexiva a todas estas ideas implica una crítica al discurso hegemónico de la modernidad.

\subsection{Reflexiones sobre la noción familia desde la crítica a la modernidad}

La idea de que existe una lógica racional y universal de las instituciones (entre ellas, la familia) como rasgo identificador de las tendencias desarrolladas con la revolución francesa a finales del siglo XVIII tiene su fundamento, de acuerdo con Lander (1998), en la cosmo-visión liberal expresada en su concepción reduccionista de la naturaleza humana, 
la naturalización de la sociedad capitalista y el contexto colonial-imperial en el cual se originó el pensamiento liberal.

El valor de la uniformidad que nace con la modernidad ha orientado la manera de entender la institución familiar como aquélla conformada a partir del vínculo legal del matrimonio, la célula básica de la sociedad, conformada por padre, madre e hijos, considerado como el modelo más racional y, por lo tanto, más válido para todos, el modelo de familia universal.

Se trata del modelo de familia construido en el marco de la modernidad, como una vía para mejorar la calidad de la fuerza productiva de la población, representativo culturalmente y reconocido como institución social por el resto de las instituciones sociales como la Iglesia y la Escuela, entre otras, para garantizar el orden del Estado moderno (Carballeda, 2001).

Desde la modernidad, se promueve el ideal de hombre libre. De acuerdo con este ideal, la familia se debe iniciar por la libre elección de los miembros de la pareja e, igualmente, la afectividad entre sus miembros debe ser de signo positivo, con relaciones inclinadas hacia la tolerancia y la armonía, lo que dará lugar a la felicidad.

Esta noción de familia que se fortalece como hegemónica con el surgimiento y desarrollo de la sociedad moderna, resalta los derechos y libertades individuales y se consolida como la célula básica de la sociedad, como un hecho natural que se instala en el imaginario social (De Jong, 2001).

En otras palabras, el "modelo universal" es considerado lo natural, lo requerido por la naturaleza humana para su desarrollo natural desde sus primeros años de existencia. Lo contrario, o lo que se aleje del modelo natural, se califica como familia atípica, incompleta, inestructurada e indeseable para la formación de las personas en su infancia (Moreno, 1998).

En resumen, el reconocimiento del pensamiento liberal promueve la instauración de la noción de familia nuclear como modelo natural hegemónico de la sociedad moderna.

Durante el siglo XIX los cuestionamientos políticos y teóricos más sistemáticos del pensamiento liberal se promovieron desde el marxismo; al cuestionar la construcción liberal de la naturaleza humana, a partir de la experiencia histórica de la sociedad capitalista y del supuesto de la igualdad político-jurídica entre los hombres en una sociedad dividida en clases antagónicas, la delimitación liberal de los ámbitos público y privado, en la cual lo público es concebido como lo importante, lo correspondiente a los hombres, mientras que lo privado es lo no importante, lo doméstico, el ámbito de las mujeres (Lander, 1998).

En este orden de ideas, para el marxismo, las condiciones materiales de existencia determinan las formas de vida social. No es natural el paso de la propiedad colectiva a la propiedad privada, de igual forma que el paso de la poligamia a la monogamia mediante el matrimonio no consiste una evolución natural de la sociedad sino qeu atiende a razones de causa mayor emparentadas a la forma de establecer el sistema de producción conjuntamente con la relación entre los hombres de tal sociedad (Engels, 1971).

En los últimos años, los desarrollos teóricos más importantes referidos al tema le han dado continuidad a la discusión, destacándose como postura más vigorosa, aquella dirigida principalmente a cuestionar ese modelo único y universal de familia, en oposición a la diversidad de modelos emergentes en la vivencia de las relaciones familiares.

Al respecto, señala Carballeda, "La familia es una realidad no homogénea en relación a la comprensión y explicación del mundo, intereses y proyectos de cada uno de sus integrantes" (2001:67).

Existe una gran variedad de formas de ser familia producto de un conjunto de fenómenos tales como: diversas condiciones de organización familiar de acuerdo con caracte- 
rísticas culturales y ancestrales específicas, los cambios en la formación y disolución de las uniones, la reducción del tamaño de las familias, aumento de familias monoparentales (materno o paterno filiales), aumento de los divorcios y, al mismo tiempo, aumento de las familias reconstituidas o de segundas nupcias, existencia de la matrifocalidad, matrilinealidad y de la matricentralidad y ausencia de procreación entre otros (Timó, 2001; Carballeda, 2001; Moreno, 1998).

El reconocimiento de la coexistencia de diversas formas de organización familiar (incluida la propia familia nuclear), distintas al modelo moderno de familia, plantea como aspecto importante el considerar el mundo material y subjetivo de las familias, constituido por su realidad en movimiento, sus pensamientos y representaciones, que se hacen presente a través de ideas que constituyen significados, contraponiéndolos a los constructos sociales simbólicos que connotan a las familias desde sus semejanzas (De Jong, 1998), lo que invita a repensar los modos de comprender la configuración familiar porque es difícil encontrar un concepto de familia que los generalice a todos.

\subsection{La diversidad familiar en el entramado social}

Existen múltiples estudios sobre la familia y, con frecuencia, cada autor presenta su definición, estando detrás de cada construcción conceptual las percepciones del mundo de quienes la proponen. Esto nos sitúa ante diversas investigaciones filosóficas, éticas, psicológicas y antropológicas, entre otras, pero, en atención a la problemática expuesta, este artículo pretende desarrollar la construcción conceptual fuera de lo doctrinario y lo dogmático, entendiendo que lo familiar no es monopolio de nadie, sino que es social y vivencialmente primordial para cada sociedad. La deliberación se ordena desde una perspectiva de totalidad con base en el contenido teórico de cada uno de los autores seleccionados.

Haciendo una breve revisión de las conceptualizaciones sobre familia, Quijada (1994) destaca la existencia de conceptos de carácter amplio o restringido. En un sentido restringido, la familia está limitada a la unión de padre, madre e hijos. De acuerdo con este criterio, se define familia como el producto de la unión entre un hombre y una mujer en matrimonio con el propósito de estar juntos, concebir y criar hijos (Pérez Castillo, 2000). Desde un criterio amplio, la familia está definida por la consanguinidad proveniente de un tronco común. En este sentido, conjuntamente con los padres y los hijos, también está conformada por abuelos, tíos, sobrinos, entre otros parientes (Quijada, 1994). Esta misma postura es asumida cuando se enuncia operacionalmente familia como grupo primario formado por padres e hijos y otros parientes que se apoyan mutuamente entre ellos y a la sociedad (Ribeiro, 2000).

Según Quiroz (2000), familia es un término con múltiples sentidos que acepta definiciones técnicas dedicadas a lograr una medición exacta del fenómeno y definiciones de 'sentido común' ajustadas a normas culturales. Asumiendo un punto de vista técnico, cada disciplina tiene una definición según el objeto específico que le ha correspondido afrontar. Así, Eroles (1998) señala la existencia de diversas acepciones cuando de definir la familia se trata. Según este autor, para la Psicología, es relevante su capacidad de desarrollo y experiencia; para la Antropología, su condición de ser representativa de la sociedad a la que pertenece; para el Derecho, resalta la vinculación jurídica.

En efecto, existen numerosas elaboraciones acerca de las diversas maneras como cada una de las disciplinas define la realidad familiar, hecho en el que es posible vislumbrar la manera como se piensa en una sociedad, además del posicionamiento y el comportamiento de lo político con respecto a la familia (Legall, 1994).

Dentro de los aportes efectuados a la comprensión del concepto de familia, destaca el realizado por Sigmund Freud (1856-1939), quien creó el trasfondo teórico y un método de análisis con influencia decisiva en la manera de comprenderla: el psicoanálisis. Desde la 
perspectiva psicoanalítica, se considera que la existencia mental y psíquica que la familia organiza en su historia permite a sus miembros lograr su salud o enfermedad a través de la modulación de los instintos humanos, la estructuración de la identificación del yo y el modo de procesar las situaciones traumáticas (Merea, 2006).

Desde una perspectiva evolutiva, para Satir (1982), la familia es el único grupo social que en un corto espacio de tiempo pasa por múltiples cambios: la concepción, el embarazo, el nacimiento, la aparición del lenguaje en los hijos, la escuela, la aparición de los maestros, la adolescencia, la independencia fuera del hogar, la menopausia y la andropausia, el climaterio, el rol de abuelos y, finalmente, la muerte de alguno de sus miembros. Según esta autora, el concepto de familia apunta a un espacio físico de convivencia humana, el lugar donde el ser humano puede recuperar el aliento para enfrentar mejor el mundo exterior.

Como lugar cultural, la familia es una agrupación elemental que afianza las creencias y valores culturales, constituyendo una institución clave en los procesos de integración social que establecen la construcción de identidades de sus miembros (Vidal, 2000). Por eso, es justo considerarla matriz de desarrollo e interacción social. La familia genera y trasmite la forma básica de valor moral: las maneras de vinculación social, que es lo que sostiene los imaginarios colectivos.

Desde la perspectiva de Lujan (2000), las definiciones de familia apuntan a un proyecto relacional que no hace referencia necesariamente a la consanguinidad, sino más bien a un contexto de aprendizaje que conecta a sus miembros con los valores socialmente aceptados, a través de un proceso de enculturación que consiste en la transmisión de representaciones y valores colectivos, indispensables para el desarrollo y adaptación del ser en sociedad.

En tanto proyecto relacional, para Maturana (1997), la familia está caracterizada por ser una red particular de conversaciones, por las peculiares coordinaciones de acciones y de emociones que constituyen su convivir cotidiano. Una manera de vivir que definió el linaje humano.

Para Loyácano (2002), la familia es una institución social afectada por los cambios que continuamente suceden en la sociedad, razón por la cual realizan nuevas prácticas familiares que las hacen diferentes (tradicionales, transicionales y posmodernas), con características propias a cada una de ellas, asume diferentes estructuras y formas de funcionamiento, sin embargo, esto no significa que sean disfuncionales.

Dentro de este orden de ideas, Rapoport y Rapoport (1982), identifican cinco fuentes de diversidad familiar: la organización interna, la cultura, la clase social, el período histórico y el ciclo vital familiar.

En síntesis, hablar de familia es hablar de diversidad, en este sentido, según Quiroz (2000), es posible clasificar la diversidad familiar a través de la construcción de la siguiente tipología:

- Hogar unipersonal, estructura unipersonal y ciclo individual: persona que vive sola. El hábitat está constituido por una sola persona, generalmente un adulto. Corresponde a personas solas que no comparten la vivienda.

- Familia uniparental/monoparental: corresponde a la unidad familiar que, desde su constitución, tiene una estructura monoparental centrada en la figura materna o paterna, o que, debido a la desintegración de la díada parental-conyugal, falta el padre o la madre.

- Uniones consensuales: son aquellas unidades familiares en las cuales hay comunidad de hechos y techos sin que se trate de un matrimonio legal. 
- Familias reestructuradas, recompuestas, o reconstituidas, simultáneas o recompuestas: es la unidad familiar que se constituye después de una desintegración, reestructurando la díada conyugal-parental a través del matrimonio o de la unión consensual.

- Familia agregada: es aquella unidad familiar formada por dos personas divorciadas, con hijos, que se casan entre sí, aportando los hijos de sus relaciones anteriores.

- Familia adoptiva: es aquella que nace de acto jurídico o resolución judicial y que se crea entre dos personas que no son necesariamente parientes.

- Hogar o unidad domestica u hogar colectivo: es una estrategia de sobre-vivencia donde las personas están unidas voluntariamente para aumentar el número de perceptores económicos y lograr economías de escala. Algunas formas de hogar más reconocidas son: cuarteles, conventos, campamentos, asilos, hospitales, hogares estudiantiles, cohabitación juvenil, etc. Como experiencias de convivencia, se registran también los hogares de niños de la calle, orfelinatos u hogares sustitutos, entre otros.

Desde la perspectiva histórica asumida, se reconoce la existencia de una amplia diversidad de formas de ser familia, expresadas en el mundo de la vida cotidiana. Constituye un espacio complejo y contradictorio atravesado por modelos hegemónicos establecidos en el discurso de la modernidad, pero donde confluyen también lo deseado por la familia y lo dado en la interrelación texto-contexto (De Jong, 2001). En resumen, se exige comprenderla como una organización en su devenir particular y contextualizado donde se relacionan tanto su mundo material como su mundo subjetivo en un movimiento tanto externo como interno.

Por consiguiente, la noción familia escapa de ser una noción solamente intelectual y se ubica en una lógica de funcionamiento de una persona o de un grupo de personas bajo la pasión de vivir juntos y compartir el relacionar afectivo en un lugar. Tal afirmación plantea la necesidad de romper con la concepción tradicional de familia como forma nuclear (papá, mamá e hijos), reconociendo otras formas de agrupación familiar que funcionan según su propia lógica.

En relación a esta postura, Del Campo (1992), afirma que es erróneo creer que existe un modelo único de familia que se transforma a consecuencia de la actuación de factores exógenos tan notorios como la actividad profesional de las mujeres, la secularización o la introducción y liberalización del divorcio. La significación dada por cada actor a su propia vivencia abre puertas a una pluralidad de conceptualizaciones constituyendo en el imaginario social la disposición a observar desde diversas perspectivas la realidad familiar, la cual, en el decir de Quiroz (2002), está signada por la heterogeneidad en la composición de las familias no por la homogeneidad como modelo hegemónico. Tal observación, sobre la pluralidad y la diversidad familiar como un fenómeno social complejo y contextualizado que puede ser definido en momentos de su devenir, invita a las ciencias que se ocupan de esta realidad a repensar el término familia, en singular, y reemplazarlo con el plural familias.

Esta noción de familias, desde su propia cotidianidad, demanda una visión de totalidad estructural y construccionista, que ubica la heterogeneidad familiar en una relación textocontexto, y en una relación pasado, presente y futuro, no desde un determinismo externo definido por teorías, sino como estructura internalizada surgida de las interacciones entre los diversos actores sociales que la conforman (De Jong, 2001).

Dentro de este orden de ideas, para las autoras del presente artículo, las diferentes configuraciones socio-culturales de las familias emplazan a romper con la visión de uniformidad familiar que nace de la modernidad y construir una nueva mirada que permita comprender el conjunto de agrupaciones familiares, reconociendo sus propias lógicas epistémicas en función de sus afectos y necesidades. 


\subsection{La noción de familia en el discurso de las trabajadoras sociales}

Los diversos enfoques con los que ha sido comprendido el concepto de familia en el Trabajo Social coinciden en registrarla como una forma de agrupación social existente en diferentes espacios y tiempos, una institución con la que esta profesión tiene mucho que ver. De esta manera, se explica como, entre los trabajadores sociales, se expresa una multiplicidad de definiciones que fueron asentadas en los registros sistemáticos llevados a cabo durante el proceso de investigación.

El total de definiciones recogidas se produjeron como fruto del consenso entre los participantes del grupo de trabajadoras sociales; no obstante, no se llegó a un consenso general que permitiera una definición única. Fue posible el acuerdo compartido de ordenarlas siguiendo criterios relativos a su conformación, papel social o condición evolutiva, entre otros, llegando a tener una imagen de las conceptualizaciones que sobre el particular manejan estos actores sociales.

Así, existen definiciones que engloban enunciaciones referidas a aquellas concepciones que la imaginan desde la conformación de la pareja y su mantenimiento:

"La familia se inicia con la decisión de una pareja de unirse legal o consensualmente y se mantiene a través de lazos de amor, confianza y solidaridad mutuos".

"Es una institución social fundada a partir de relaciones de parentesco, reguladas por pautas y prácticas sociales establecidas, y afirmada como el foco de la estructura social, es decir, un elemento más dentro del sistema social que actúa como socializador primario, que antecede a la escuela y otros grupos sociales".

Estas definiciones distinguen la intimidad al interior de la dinámica familiar con respecto al papel socializador que se le asigna a la institución familiar, abordando la polémica sobre si es un espacio privado o público.

Resalta, en este sentido, una mirada desde las relaciones afectivas y la importancia de elementos que promocionen la participación, porque:

“....una familia es la creación de un espacio de relaciones entre sus miembros, esto es, la pareja con los hijos y otros parientes, basadas en el respeto mutuo, el diálogo y la participación".

Desde este punto de vista, parece que se entiende la importancia de su papel en el desarrollo de la producción y reproducción de la vida cultural, observándola:

“... como un grupo fundamental de la sociedad en el cual los seres humanos realizan sus procesos de nacimiento y desarrollo, a través del cumplimiento de funciones de protección social a sus miembros, además de preservar y transmitir valores y tradiciones a las futuras generaciones".

Esto implica el reconocimiento de condicionantes interiores y exteriores existentes en sus intermediaciones en la relación individuo/sociedad, ya que:

“... sirve de intermediario con el individuo en la sociedad manteniendo y proyectando la vida humana y se constituye en un especie de interprete de las personas hacia la sociedad a la vez de la sociedad a la persona, la familia sirve a sus miembros y a la sociedad, la forma como se realice esta intermediación entre la personas y la sociedad. Está directamente relacionada con las relaciones históricas y las dinámicas societales, así como también por la etapa del ciclo familiar, los cambios o condicionantes internos y externos que afectan al núcleo."

Este último aspecto constituye una afirmación acerca de la visión de la vida familiar en su evolución, que se manifiesta en las creencias personales relativas a los papeles parentales:

“Ambos protagonistas familiares deben asumir sus responsabilidades en la formación de sus hijos, bajo un criterio de mutuo acuerdo y tratamiento; sin olvidar el proceso evolutivo de los mismos, porque los que hoy son niños o niñas, después serán adolescentes, luego adultos y, al igual que sus padres, se enfrentarán a los mismos compromisos". 
Por otro lado, surgen voces referidas a la ubicación del espacio de vida familiar, definiendo familia como:

"Conjunto de personas que viven habitualmente bajo el mismo techo y que, por otra parte, están ligadas entre ellas por lazos de parentesco, afinidad, afecto o amistad".

Quizás esta definición esté relacionada con la actividad que le ha dado concreción desde sus orígenes a la vinculación trabajo social / familia, se trata de la visita domiciliaria.

Una definición, que probablemente también esté relacionada con las acciones propias del ejercicio de los trabajadores sociales es la siguiente:

"La familia tiene un papel estelar en las acciones comunitarias para el mejoramiento de la calidad de vida en la salud, la estructura humana y la construcción de la vivienda, así como en la formación de diferentes tareas que organizan la vida en sociedad, tales como la recreación, la educación, la atención a los niños y a los adolescentes".

Un aspecto en el que existe coincidencia entre los trabajadores sociales participantes de este estudio acerca de la necesidad de avanzar hacia conceptualizaciones de familia que reconozcan la diversidad de la familia venezolana:

“... en la familia venezolana, la conformidad padre, madre e hijos no es el único patrón existente en el mundo popular, con el que nos relacionamos, ya que la heterogeneidad de esta estructura se manifiesta a través de la coexistencia de varios tipos de vida familiar".

De esta manera, la diversidad familiar se encuentra expresada en los discursos cotidianos, sin embargo, aún hoy, en los textos escolares, continuamos observando nociones de familia en singular, en correspondencia con las ideas de homogeneidad y uniformidad.

III. REFLEXIONES FINALES: Hacia una posición reflexiva ante las diferentes nociones de familias

En el campo de las Ciencias Sociales, cada disciplina se diferencia por el modo de aproximarse a la realidad, el modo de mirar y de intervenir lo social. En este caso, el modo como profesionales del Trabajo Social se acercan al tema familiar va a depender de su posición epistémica. En este sentido, encontramos desde una concepción homogeneizadora y uniforme de familia hasta una concepción pluralista o emancipadora.

A partir de la concepción homogeneizadora de la naturaleza humana se responde al discurso propio de la modernidad, considerando la familia una institución natural que, independientemente de su momento histórico, debe cumplir con su rol socializador para la reproducción de la vida en sociedad (De Jong, 2001). Dentro de tal concepción, se encuentra una noción imaginada desde la conformación de la pareja y su mantenimiento.

Desde esta óptica, se cumple un papel instructor que consiste en moralizar los valores de la modernidad, a través de una socialización progresiva escolar que trasciende a lo familiar, sobre la base de la representación del modelo nuclear de familia naturalizado, que contribuye a nutrir vínculos sociales de orden jerárquico y de sometimiento (Cichelli y Cichelli, 1998).

No obstante, las complejas relaciones entre profesionales del Trabajo Social y familias, vivenciadas en el día a día, exigen una concepción pluralista y emancipadora que reconozca los condicionantes interiores y exteriores existentes en sus intermediaciones en la relación individuo/sociedad la diversidad familiar, relacionada con las acciones propias del ejercicio de los trabajadores sociales, donde se manifiestan las creencias personales relativas a los papeles parentales.

Es evidente que las familias tienen diferentes formas de asumirse, dada su capacidad de reinvención. En este sentido, estamos ante múltiples formas familiares que se construyen desde las cotidianidades y se alejan de la concepción normalizada por la racionalidad 
moderna, siendo los propios hechos familiares los que nos aporten los elementos para reflexionar en torno a las diferentes nociones de familia en el discurso escolar.

En síntesis, el reto actual para estos profesionales en nuestro país es asumirse como actor social, crítico y emancipador al reflexionar sobre las realidades familiares existentes en los contextos escolares. Para lograrlo, será necesario irrumpir la homogeneidad del discurso heredado de la modernidad con discursos sociales emergentes, una tarea encomendada.

\section{BIBLIOGRAFÍA}

CARBALLEDA, A. "Las políticas sociales y la esfera de la familia, crisis de legitimidad y representación" en La familia en los albores del milenio, Reflexiones interdisciplinarias un aporte al trabajo social. Espacio Editorial Buenos Aires, 2001, pp. 22-35.

CICHELLI- PUGEAUlT, C.; CICHELLI, V. Las teorías sociológicas de la familia. Ediciones Nueva Visión. Buenos Aires, 2001, pp. 3-15.

DE JONG, E. (2001) “Trabajo Social, familia e intervención” en La familia en los albores del milenio, Editorial Espacio, Buenos Aires, 2001, pp. 2-20.

DEL CAMPO, A. La nueva familia española, Editorial Eudema, Madrid, 1992, pp. 2-10.

ENGELS, F. “El origen de la familia, la propiedad privada y el Estado”, De las Obras escogidas (en tres tomos) de MARX, C. y ENGELS, F., Editorial Progreso, Tomo 3, Moscú, 1971, pp. 203-352.

EROLES, C. Familia y Trabajo Social, Editorial Espacio, Buenos Aires, 1998. Págs. 130-172.

GIL CALVO, E. Identidades complejas y cambio biográfico. Universidad Complutense, Madrid. 2001, pp. 3-7.

LANDER, E. Hacia una refundación de la teoría democrática. ECOSOC (Economía y Ciencias Sociales) Universidad Central de Venezuela, Caracas, 1998, pp. 1-4.

LEGALL, D. Aproximación sociológica al estudio de la familia. Editorial de la Universidad del Zulia. Maracaibo, 1994, pp. 8-23.

LOYACANO, I. Contextos, familias y terapeutas. Sociedad argentina de terapia familiar, Buenos Aires. 2002, pp. 3-9.

LUJAN, M. "Familia y Educación en valores". Foro Iberoamericano sobre la Educación en Valores, Santiago de Chile, 2000, pp. 2-6.

MATURANA, H.; ZOLLER, G. Amor y Juego, fundamentos olvidados de lo humano, Editorial Instituto de Terapia Cognitiva, Santiago de Chile. 1997, pp. 19-69

MEREA, C. Familia, psicoanálisis y sociedad: el sujeto y la cultura, Fragmento en Fondo de Cultura Económica https://www.fcear.com/capit_solicitar.asp?CAP=217\&CAT=EP - 7k -, 2000.

MORENO, A. La familia popular venezolana, Primera Fundación del Centro Gumilla. Caracas, 1998, pp. 5-12.

PÉREZ CASTILlO, O. Epílogo en familia, un arte dificil. Fundación Venezuela en Positivo. Caracas, 2000, pp. 703-712.

QUIJADA, A. La familia y el derecho a la educación, Editorial de la Universidad del Zulia EDILUZ, Maracaibo, 1994, pp. 8-15.

QUIROZ, M. "La matriz familiar en la era de la mundialización”, Ponencia presentada en el IV Congreso Nacional y II Internacional de Trabajo Social. Memorias 2. Publicaciones de la Facultad de Ciencias Jurídicas y Políticas de la Universidad del Zulia, Maracaibo, 2000.

RAPOPORT, R.; RAPOPORT, R.N. "British families in transition”, In R.N. RAPOPORT; R. RAPOPORT; M.P FOGARTY, R (eds), Families in Britain (pp. 475-499), Londres, 1982.

RIBEIRO, M. Familia y Política Social, Grupo Editorial Lumen. Buenos Aires. 
SATIR, V. Nuevas relaciones humanas en el núcleo familiar, Editorial Pax. Mexico Distrito Federal, 1982, pp. 15-32.

TIMÓ, E. "La familia, una mirada desde la Antropología Social" en DE JONG: La familia en los albores del milenio, Editorial Espacio, Buenos Aires, 2001, pp. 37-43.

VIDAL, F. El devenir de la familia. Artículo disponible en http://www.psicoterapeutas.org/devenir.htm, 2000. 